\title{
OPTIMIZATION OF NATURAL GAS COMBUSTION IN FURNACE OF STEAM BOILERS
}

\author{
Murot Tulyaganov ${ }^{1}$ \\ ${ }^{1}$ Tashkent State technical university, Department of Electromechanics and Electrotechnologies, Universitetskaya - 2, \\ Tashkent, 100095, Uzbekistan
}

\begin{abstract}
The issues of natural gas combustion control in the furnace based on the compile mathematical model to optimize the combustion process using a frequency-controlled asynchronous electric drive of blow fans are considered in this article.
\end{abstract}

Natural gas and air are separately supplied to the furnace to produce steam in a natural gas steam boiler. A gas mixture with theoretically necessary air for complete combustion is called a stechnometric mixture. However, it is impossible to achieve complete combustion of the fuel if only the theoretically necessary amount of air is supplied to the furnace. This is due to the fact that it is difficult to move fuel with air so that the required number of air molecules is supplied to each fuel molecule. Therefore, in practice, it is necessary to supply more air than is theoretically necessary, that is, to work with excess air. At the same time, part of the air passes through the furnace without reacting with fuel [1-6].

The amount of excess or shortage of air is determined by the air flow factor $\alpha$, which shows the ratio of the actual amount of air consumed for combustion to the theoretically necessary one (fiq.1).

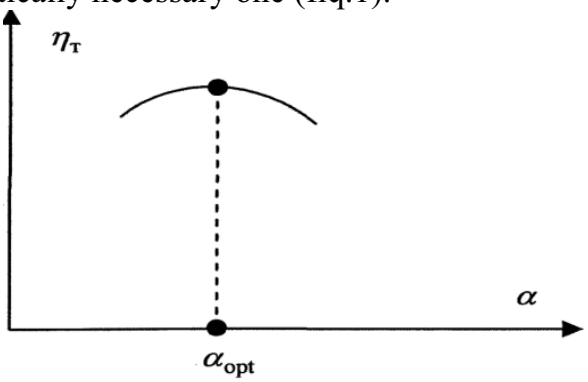

Fig.1. Dependence of the boiler efficiency from the excess coefficient

The excess air coefficient is determined by the ratio:

$$
\alpha=\frac{Q_{\text {air }}}{Q_{\text {air.min }}}
$$

where $Q_{\text {air }}$ - air supply to the furnace, Qairmin minimum air flow required for complete fuel combustion.

The need to burn fuel, at $\alpha$ close to 1.0 , is entirely caused by the desire to ensure the most economical and efficient operation of the unit. The less $\alpha$, the less heat the exhaust gases will take away. In addition, the increase $\alpha$ reduces the temperature in the furnace, which causes the gas to burn less actively and combustion may become incomplete. By achieving combustion of gas with the smallest $\alpha$, it cannot be reduced so that combustion becomes incomplete, since even a small insufficiency of combustion leads to very significant heat losses [7-9].

Currently, gas combustion methods are being developed and successfully implemented, especially on large steam boilers, which, without reducing efficiency, drastically reduce the content of harmful substances in combustion products. The most effective method is to organize a smooth control of the speed of the blow fan, which optimizes the combustion process of natural gas in the furnace.

In the furnace, due to the oxidation of air nitrogen, gas oxides are formed. Their quantity is determined to a decisive extent by the maximum temperature in the combustion zone, as well as the concentration of reacting substances (nitrogen and oxygen) and the contact time between them. A decrease in concentration, that is, the possibility of burning gas at the proportionality of the theoretical and real value of the amount of air in the furnace, leads to a decrease in the amount of nitrogen oxides formed. With a significant excess of air, the concentration of oxidized nitrogen also decreases, since in this case a decrease in the temperature in the combustion zone has a greater effect [10-12].

The following scheme of the fuel-air control system (fiq.2) can be used in the operation of a natural gas boiler in large steam boilers to optimize the combustion process of natural gas.

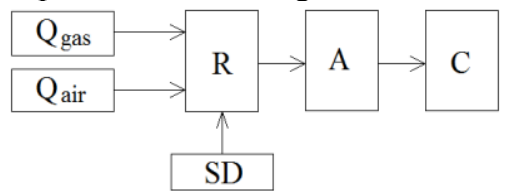

Fig.2. Block-structural diagram of "fuel-to-air" air control by gas and air flow rates:

Qgas - gas flow; Qair - air flow; R - regulator; A - actuator; C control; SD - setting device 
In the block-structural diagram, the combustion process of the gas in the furnace is controlled by signals received from the setting device. To optimize the combustion process in the furnace, we compose a mathematical model that allows us to maintain gas and air in the amount necessary for the complete combustion of gas. Taking into account that natural methane gas is used in steam boilers, the air flow rate required for burning $1 \mathrm{~m}^{3}$ of methane is $9.52 \mathrm{~m}^{3}$ [13$14]$.

The simplified mathematical model for the blockstructural fuel-air control scheme for natural gas and air flow rates is:

$$
Q_{\text {air }}=9.52 Q_{\text {gas }} .(1)
$$

Entry conditions: initially we accept that the gas flow rate is unchanged $Q_{\text {gas }}=$ const, air flow rate is adjustable parameter $Q_{\text {air }}=$ var .

By the power expression of the drive engine, we determine the fan air flow rate

$$
Q_{\text {air }}=\frac{P_{S} \eta}{P_{\text {air }}}=\frac{\omega_{S}(\alpha) M_{S}(\alpha) \eta}{P_{\text {air }}},(2)
$$

where $\mathrm{P}_{\mathrm{s}}-$ mechanical power on the shaft; $\omega_{\mathrm{s}}$ - angular speed of the drive motor corresponding to the static torque of the fan $M_{s} ; \eta$ - overall fan efficiency.

We substitute the expression (2) in the expression (1) and write it in a modified form

$$
\frac{\omega_{s}(\alpha) M_{S}(\alpha) \eta}{P_{\text {air }}}=9.52 Q_{\text {gas }}
$$

For a blow fan, the initial static torque at the rotating mechanism can be taken as $\mu_{s}=0.15$. Therefore, the value of the static torque will change according to the law

$$
M_{s}=0.15 M_{\text {snom }}+0.85 M_{\text {snom }} \alpha^{2}(1-s)^{2},(4)
$$

where $\mathrm{M}_{\text {snom }}$ - nominal value of fan static torque; $\alpha=$ $\frac{f_{1}}{f_{1 \text { nom }}}$ - relative frequency value; $f_{1}$ and $f_{1 \text { nom }}$ respectively the operating and nominal values of frequency; s - slip.

Based on equations (3) and (4), we compose a system of equations of the mathematical model of optimal control of the combustion process in the furnace

$$
\left.\begin{array}{c}
\frac{\omega_{s}(\alpha) M_{S}(\alpha) \eta}{P_{\text {air }}}=9.52 Q_{\text {gas }} \\
M_{s}=0.15 M_{\text {snom }}+0.85 M_{\text {snom }} \alpha^{2}(1-s)^{2}
\end{array}\right\} .
$$

In the presented mathematical model (5) of optimal control of the combustion process in the furnace, the variable parameter is the voltage frequency of the stator winding supplying the fan asynchronous motor. During the combustion process, non-compliance with the condition of proportionality of gas $\mathrm{Q}_{\text {gas }}$ and air $\mathrm{Q}_{\text {air }}$ flow rates is eliminated by adjusting the speed of the driving fan asynchronous motor, and thereby the proportionality of the flow rates of both components is ensured. Therefore, the only correct solution to optimize the combustion process is the use of a frequency-controlled asynchronous electric drive for the fan in the furnace [15-18].

Considering that the angular velocity of the drive motor is $\omega_{s}(\alpha)=2 \pi f_{1}$, we convert the system of equations (5)

$$
\begin{gathered}
0.3 M_{\text {snom }} \pi f_{1 \text { nom }} \eta \alpha+1.7 \pi f_{1 \text { nom }} M_{\text {snom }}(1- \\
s)^{2} \eta \alpha^{3}-9.52 Q_{\text {gas }} P_{\text {air }}=0 .(6)
\end{gathered}
$$

If we enter the following symbols:

$\alpha_{1}=1.7 \pi f_{1 \text { nom }} M_{\text {snom }}(1-s)^{2} \eta, \quad \alpha_{2}=0, \quad \alpha_{3}=$ $0.3 M_{\text {snom }} \pi f_{1 \text { nom }} \eta, \alpha_{4}=-9.52 Q_{\text {gas }} P_{\text {air }}$, the result is:

$$
\alpha_{1} \alpha^{* 3}+\alpha_{2} \alpha^{* 2}+\alpha_{3} \alpha^{*}+\alpha_{4}=0, \text { (7) }
$$

where $\alpha^{*}$ - optimal adjustable parameter - frequency of voltage of the stator winding feeding the asynchronous motor of the fan.

When the order of the algebraic equation in expression (7) is high $(n \geq 3)$, finding an analytical solution is difficult, so numerical methods of solving are used.

This problem can be solved by the following numerical method [19-20].

To calculate an adjustable parameter $\alpha^{*}$ from an algebraic equation, we use one of the numerical methods [5]: iteration method, half division method, or Newton method.

Denote the left side of the expression (7) as $F(\bar{A}, \alpha)$.

$$
F(\bar{A}, \alpha)=0,(8)
$$

where $\bar{A}=\left[\alpha_{1}, \alpha_{2}, \ldots, \alpha_{n+1}\right]$ - algebraic equation coefficient vector.

Newton's method is effective for solving those equations for which the value of the modulus of the derivative $\left|F_{\alpha}^{\prime}\right|$ near the root is large enough, that is, the graph of the function $\mathrm{F}$ in the vicinity of this root has a large steepness. To solve the algebraic equation, it is advisable to apply the Newton method. The block diagram of the algorithm for solving equation (8) according to the Newton method is given in Fig.3.

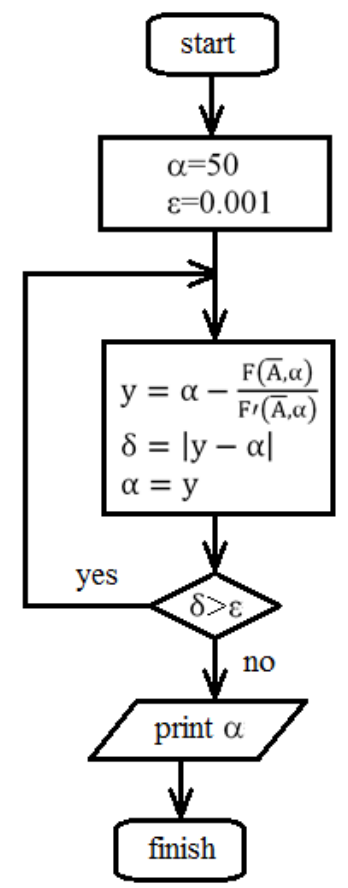

Fig.3. The block diagram of the algorithm for solving equation (8)

The use of a frequency-controlled asynchronous electric drive with a frequency converter for controlling fans ensures [21-24]:

- the complete elimination of current overloads of the engine;

- reduction of power consumption by $10-50 \%$ due to failure of gate control; 
- automatic maintenance of temperature in air ducts at changes of equipment operation modes;

- possibility of accurate dosing and increased efficiency of combustion processes.

As a result, fuel consumption decreases by $3-10 \%$ at the same boiler capacity. The combination of fuel combustion at low values and the amount of air equal to its theoretical value with the recirculation of combustion products allows reducing the amount of nitrogen oxides formed by $70-90 \%$ during gas combustion.

\section{References}

1. Chepel V.M., Shur I.A. Combustion of gases in the furnaces of boilers and furnaces and maintenance of the gas economy of enterprises. - 8th ed., Processing and additional - S.-P.: Nedra, 1990. - 591 p.

2. Imomnazarov A.T., Azamova G.A. Energy-saving modes of asynchronous motors operation. Monograph. - T: ToshDTU, 2014. - 140 p.

3. Hoshimov O.O., Imomnazarov A.T. Energy saving of electromechanical systems. T: Fan va texnologiya, 2015. - $155 \mathrm{p}$.

4. Syromyatnikov I.A. Modes of operation of asynchronous and synchronous electric motors. - M.: Gosenergoizdat, 1984. - 527 p.

5. Svetozarova G.I., Sigitov E.V., Kozlovsky A.V. Workshop on Programming in Algorithmic Languages. M.: Nauka, 1980. - 320 p.

6. Saidkhodjaev A G, Najimova A M and Bijanov A K 2019 Method for determining the maximum load of consumers in city power supply systems E3S Web Conf 139 doi:10.1051/e3sconf/201913901078.

7. Taslimov A D, Rakhmonov I U 2019 Optimization of complex parameters of urban distribution electric networks Journal of Physics: Conference Series 1399 doi:10.1088/1742-6596/1399/5/055046

8. Rakhmonov I U, Niyozov N N 2019 Optimization setting of steel-smelting industry in the issue of alloy steels E3S Web Conf 139 doi:10.1051/e3sconf/201913901077

9. Rakhmonov I U, Nematov L A, Niyozov N N, Reymov K M and Yuldoshev T M 2020 Power consumption management from the positions of the general system theory Journal of Physics: Conference Series 1515 doi:10.1088/1742-6596/1515/2/022054

10. Rakhmonov I U, Reymov K M, Najimova A M, Uzakov B T and Seytmuratov BT 2019 Analysis and calculation of optimum parameters of electric arc furnace Journal of Physics: Conference Series 1399 doi:10.1088/1742-6596/1399/5/055048

11. Taslimov A D, Berdishev A S, Melikuzuev M V and Rakhimov F M 2019 Method of selecting parameters of cable lines distributive networks $10 \mathrm{kV}$ in uncertainty conditions E3S Web Conf 139 doi:10.1051/e3sconf/201913901082

12. Taslimov A D, Berdishev A S, Melikuziyev M V and Rakhimov F M 2019 Method of choosing the unification of cable sections of electric network cables under conditions of load development uncertainty E3S Web Conf 139 doi:10.1051/e3sconf/201913901081
13. Rakhmonov, I.U., Berdishev, A.A., Khusanov, B.M., Khaliknazarov, U., Utegenov, U. (2020) General characteristics of networks and features of electricity consumers in rural areas Journal of IOP: Conference Series. MIP: Engineering-2020. 883 (2020) 012104 doi:10.1088/1757-899X/883/1/012104

14.E.G.Usmanov, A.N.Rasulov, M.K.Bobojanov, R.Ch.Karimov. E3S Web of Conferences 139, 01079 (2019), doi.org/10.1051/e3sconf/201913901079

15. Bobojanov M.K., Rasulov A.N., Karimov R.Ch., Sattarov H.A. Bulletin Descendants of Mohammed AlKhwarizmi (ISSN: 2181-9211), Tashkent, 3(5), PP.106-109, (2018).

16. Burievich, T.J. The questions of the dynamics of drilling bit on the surface of well bottom// Arch. Min. Sci. -Poland. - Vol. 61 (2016). - №2. - P. 279-287. DOI 10.1515/amsc-2016-0020.

17. Hoshimov, F.A., Bakhadirov, I.I., Erejepov, M., Djumamuratov, B. (2019) Development of method for normalizing electricity consumption E3S Web Conf 139 doi:10.1051/e3sconf/201913901074

18. G.R.Rafikova, M.R.Ruzinazarov, S.K.Makhmutkhonov. E3S Web of Conferences, 139, 01075,

https://doi.org/10.1051/e3sconf/201913901075

(2019),

19. Safarov J.E., Sultanova Sh.A., Dadayev G.T., Samandarov D.I. Method for drying fruits of rose hips. // International Journal of Innovative Technology and Exploring Engineering. Vol.9, Iss.1. 2019. P.37653768,.

20. Safarov J.E., Sultanova Sh.A., Dadayev G.T., Samandarov D.I. Method for the primary processing of silkworm cocoons (Bombyx mori). // International Journal of Innovative Technology and Exploring Engineering. Volume-9, Issue-1, November, 2019. P.4562-4565.

21. Allayev, K.R., Fedorenko, G.M.,Postnikov, V.I.,Ostapchuk, L.B. Asynchronous generators as power system's natural dampers. 43rd International Conference on Large High Voltage Electric Systems 2010, CIGRE 20102010, 9p43rd International Conference on Large High Voltage Electric Systems 2010, CIGRE 2010; Paris; France; 22 August 2010.

22.Fazylov, Kh.F.,Allaev, K.R. Analysis of the operation of an electrical system during simultaneous operation of synchronous and asynchronous generators. Power engineering New York Volume 18, Issue 3, 1980, Pages 81-88.

23.Fazylov, Kh.F.,Allaev, K.R. Asynchronous turbogenerators with stator excitation and the prospects for their utilization. Power engineering New York Volume 23, Issue 2, 1985, Pages 7-13.

24.Fazylov, Kh.F.,Allaev, K.R. Calculation and experimental analysis of conditions of electrical power systems containing induction generators Power Engineering New York Volume 27, Issue 6, 1989, Pages 27-34. 